\title{
Effect of Social Skills Training on Self Concept of Teenage Mothers, A case study of Training College in Kenya
}

\author{
Chinyere Okore $^{1}$ (D), Stephen Asatsa ${ }^{2}$, Maria Ntarangwe ${ }^{3}$ \\ 1,2,3 Department of Counseling Psychology, The Catholic University of Eastern Africa, Nairobi Kenya.
}

\begin{abstract}
Keywords:

Training on Social Skills, Self-Concept, Teenage Mothers,

Training College,

Purpose of Study: The purpose of this study was to explore the effectiveness of social skills training on enhancing self-concept of teenage mothers in Kibera. Because teenage pregnancy is considered as a global issue. A large proportion of teenage mothers give up on themselves and struggle with negative emotions resulting from societal stigma, rejection and isolation from friends and families, which can lead to poor self-concept.
\end{abstract}

Kenya.

Received Date:
17-02-2021

Accepted Date:

25-07-2021

Publication Date:

31-07-2021

\begin{abstract}
Methodology: The study was anchored on person centered theory of Carl Rogers and Bandura`s social cognitive theory. Mixed method sequential explanatory design was adopted for the study. The target population was 150 teenage mothers. Quantitative data was collected from participants using selfconcept and social skills questionnaires. An interview guide was used to collect data from one social worker and one school administration for the qualitative study. The data were analyzed utilizing narratives and correlations. We used SPSS version 21 to examine the first round of quantitative data. After analyzing the quantitative data, individuals with mean scores between 1.0 and 2.5 were chosen for the qualitative investigation.
\end{abstract}

Main Finding: The study found out that social skills training has improved self-concept of teenage mothers in Kibera. The qualitative study revealed that teenage mothers go through psychological and emotional challenges in the hands of their parents. The study generally concludes that self-concept of teenage mothers is being affected by lack of psychological support, forgiveness and acceptance from the family. Intervention suggested included being emotionally present, psychological support, and love by parents to teenage mothers.

Research Implication: The study's findings suggested that rules on guidance and counseling services for parents and teenage mothers be strengthened in order to improve assertiveness. It is critical for social workers to focus on policy development in low-income households, particularly in the area of education, in order to prevent adolescent pregnancy.

Novelty/Originality of this study: Based on the findings, this study proposes a novel approach to dealing with teen pregnancy and offering psychological support. In addition, the parents provide social support and love.

\section{INTRODUCTION}

According to the Organization (2018), about 16 million young girls between the age of 15 and 19 years and about one million girls younger than 15 years give birth every year. Studies carried out in the unites States found out that teenage girls less than 20 years old give birth to approximately 400,000 babies (Boobpamala, Kongvattananon, \& Somprasert, 2019). Teenage pregnancy has long-term psychological implication that affect teenage mothers' self-concept and some cases had led to a susceptible repeated pregnancy and poor self-understanding. Those who escaped early marriage are taken back to school without adequately preparing them psychologically and emotionally. Consequently, teenage mothers from low-income background and poor educational attainment are likely to experience challenges in their everyday interpersonal relationship making them feel socially isolated, marginalized and rejected by others (Sang, 2015). These notion amounts to the challenges they face in the society making these teenage mothers develop poor self-concept. Sámano et al. (2017) in their study found out that teenage mothers complained of poor family relationship and communication which led them seeking love outside the family. Many of the challenges they face as adolescence are related to lack of unconditional love and support from families making them vulnerable to unprotected sexual relations without fear of pregnancy. Due to the long-term implication to self-concept and psychosocial adjustment following teenage pregnancy, some of these girls opt for illegal abortion; hide in shame, and feel guilty, depressed and abandoned (Gaspar, Cerqueira, Branquinho, \& Matos, 2018). A qualitative research by Ellis-Sloan and Tamplin (2019) and Fearnley (2018) opined that teenage motherhood have an awareness of their stigmatizing identity, and this affects how they present themselves. Fostering on some of the strategies employed in rehabilitating teenage mothers to enable them rebuild poor self-concept, few studies have made a plausible contribution. A distinction was made by (Paik, 1992) study in the

${ }^{1}$ Corresponding Author: okorechinyere1976@gmail.com 
USA suggesting various support services as a long-term approach to improve self-concept of teenage mothers ranging from models and significant others in the teenagers' lives that may help improve in moral-ethical, family and social interaction. In Africa, Studies have confirmed that the shame of becoming a mother at that young age leads to anxiety, depression and selfdefeating thought of shattered dream and lack of purpose in life. In view of a study carried out by Mohamed and Mahmoud (2018) in Egypt found out that some of the factors linking teenage pregnancy with self-concept is societal and cultural stigmatization resulting to shame and self-defeating behaviour. According to Anyamene and Obumneke (2021) when these teenage mothers lack the potential and confidence to face challenges of life, they resort to withdrawal, become nervous, timid, defensive, aggressive, and inability to maintain stable relationship and poor communication skill. This explains different psychological tortures they experience ranging from expulsion from school, social exclusion, and family and friends' rejection leading to poor self-concept. Literatures reviewed on social skills as an intervention on the self-concept of teenage mothers in Kenya have not explored so much on effectiveness of social skills in raising poor self-concept of teenage mothers. They are receiving academic and economic empowerment yet training them on social skills aiming at improving their poor self-concept has not been prioritized in this case. In Kenya, high increase of early pregnancy has long been a societal challenge. A survey carried out by Okore, Asatsa, and Ntarangwe (2021) on teenage pregnancy reported that Nairobi County is leading with 11,795 teenage pregnancies from January to May 2020. This increase raised a concern to stakeholders, parents, religious communities and political leaders. Being pregnant as a teenager is devastating which leads to loss of confidence and the individual struggles with self-worthiness, body image and shame. There is urgent need to address teenage pregnancies by fully funding and implementing psychosocial and social skill programs to rebuild teenage mothers' self-concept. Hence, empowering them on decision-making, self-awareness, assertive behaviour to avoid repeat pregnancies. Negligence of this will make them vulnerable to their perpetrators and susceptible to getting more pregnancies. Currently, the problem is being addressed by introducing psychosocial support and teenage mother's project aiming at empowering them economically and adjust to this new role and life transition (Kumar, Stecher, Li, Knyaz, \& Tamura, 2018).

\section{LITERATURE REVIEW}

Parray and Kumar (2017) carried out a study in India adopting quasi-experimental design to investigate the impact of assertiveness training on self-esteem, stress, psychological well-being, and academic achievement among adolescents. The study purposively sampled 13 students within the age range of 16 to 19 years. The results of the study showed a significant improvement in the students' level of assertiveness and self-esteem. The researcher concluded that Assertive training helps to improve the level of assertiveness, self-esteem. Shanmugam and Kathyayini (2017) carried out a study in India to examine the relationship between assertiveness and self-esteem among adolescents. The study adopted descriptive correlation research approach and random sampled 60 adolescents from selected children hospital. The findings showed a significant positive correlation of ( $\mathrm{rs}=0.64)$ between the assertive behaviour and self-esteem of the adolescents). This finding is relevant to the present study in that, it examined the effectiveness of assertion behaviour in relation to age and educational level, which constitute part of the intervening variable in the present study. Okore et al. (2021) conducted a study to examine the relationship between self-concept and aggressive behavior among deaf adolescence in Egypt. A convenience sample of 60 deaf students from the above-mentioned settings were recruited. The results showed that majority of the participants of the study have low self-concept. The current study examined the effectiveness of social skills training on enhancing self-concept of teenage mother using mixed methods sequential explanatory design and census method to sample more participants, hence, generate new subjective experience of the participants. Nihayati, Tristiana, Junata, and Yusuf (2017) conducted a quasi-experimental research design in Indonesia to explain the effect of social skills training on self-efficacy. The population of the study consisted of 43 clients in the mental hospital and sampled 30 participants. Results showed that social skill training had significant effect in improving the ability of the clients to interact with others. The study is relevant to the present study as it draws attention to the issues of the effectiveness of social skills training on enhancing self-concept of teenage mothers in Kenya using mixed methods sequential explanatory design in order to establish new subjective experience of the participants.

A study on predictors of social skills among adolescents' girls $(\mathrm{N}=364)$ was carried out by Morowatisharifabad, Baghernezhad Hesary, Sharifzadeh, Miri, and Dastjerdi (2019) in Iran. The study examined the status of life skills and selfesteem in relation to age, relationship management among Iranian teenage girls. The findings showed that there was a significant association between life skills and self-esteem $(\mathrm{p}<0.05)$. This is relevant to the study as it brought out clearly the significant association between social skills and relationship management among teenage girls, which could also apply to self-concept among teenage mothers in Kenya adopting mixed method sequential explanatory design.

Kuasit, Chunuan, Hatthakit, and Bullock (2018) conducted a study in China to evaluate the effectiveness of Nursing Program as a strategy in enhancing and building resilience in pregnant teenagers. The findings revealed that the participants in the experimental group had a significantly greater improvement in mean score of life goals than did the control group. Okore et al. (2021) carried out a study in Kenya to investigate the influence of life skills training on teenager's behavior. The study concluded that life skills training equipped students in making right decisions, voicing out their opinion before making conclusion on matters, to be able to solve problems and become more assertive.

\section{METHODOLOGY}

The study was carried out at St Charles Lwanga Vocational Training College in Kibera, Nairobi County, Kenya. According to Kenya Water and Health Organization, Kibera is an informal settlement situated in Nairobi's Southwestern Peri-urban zone approximately seven kilometers from the Nairobi City Centre. The County has a population over 250,000 according to the 2019 census mostly from different parts of the country. The residents of Kibera encompass different ethnic groups and races found within that country. St Charles Lwanga Vocational College is located in Raila village along Kibera Southern by-pass off Ngong forest.

Please cite this article as: Okore, C., Asatsa, S., \& Ntarangwe, M. (2021). Effect of Social Skills Training on Self Concept of Teenage Mothers, A case study of Training College in Kenya. Journal of Social Sciences and Economic Review, 3(2), 1-09. doi.org/10.36923/ijsser.v3i2.102 
The choice of the locale is based on the observable experience of the rehabilitation training college that one of the psychological effects of teenage pregnancy is poor self-concept and this location has a high concentration of teenage mothers who are enrolled at the rehabilitation program. This motivated the researcher to examine the effectiveness of social skills training on enhancing self-concept of teenage mothers in that location to increase their self -concept. According to Kuasit et al. (2018), a study location is selected because of existence of a problem.

The study population comprised 150 teenage mothers, a social worker and the administrator of the college. The information was derived from the document analysis from the school record.

The study used mixed methods sequential explanatory design. The mixed methods sequential explanatory design consists of two distinct phases: quantitative followed by qualitative (Creswell, Plano Clark, Gutmann, \& Hanson, 2003). In this design, the researcher first collected the quantitative data using standardized and self-developed questionnaires in form of Likert scale. After collecting quantitative data, those whose means score were between 1.0 and 2.5 were purposively selected for the qualitative study which was an indication of low self-esteem to create new subjective experience of the participants on the effects of social skills training on enhancing their self-concept. The second qualitative phase helped to explain the quantitative results obtained in the first phase. The results build on the first quantitative phase were connected in the intermediate stage in the study. The rationale for this approach is that the quantitative data and their subsequent analysis provided a general understanding of the research problem.

The study adopted a census method to select all the teenage mothers for quantitative study, extreme case-sampling technique was used to select those with low mean score on self - esteem for qualitative study. Purposive sample was used to select one social worker and the administrator.

The data collection Instrument for the study were a standardized questionnaire, a researcher`s self- developed and modified questionnaire, and interview guide. Hence, the researcher used self-efficacy scale, relationship management scale, selfawareness scale, self-monitoring scale, Rosenberg self-esteem scale and assertiveness scale for the quantitative data and semistructured interview guide was used to collect qualitative data.

Self-Esteem was a 10 items Likert scale adapted from Alessandri, Vecchione, Eisenberg, and Łaguna (2015) self-esteem scale, which is a brief unidimensional measure of global self-esteem originally. This scale was developed by Rosenberg to measure self-esteem in adolescents. This questionnaire was used to measure teenage mother's self-esteem. The researcher adopted any mean score between 1.0 and 2.5 to be an indication of low self-esteem Permission to use this questionnaire is generally given and researchers do not have to seek for permission to use it. The pilot test helped to ascertain the quality of the tool in this study. Through pilot testing, the scale reported a Cronbach's alpha coefficient of 0.873 , which indicated a high reliability of the instrument according to Creswell (2014).

Self-Monitoring was 4 items Likert scale of Self-Monitoring Scale (SMS) with norms that are based on guidelines provided by Bing, Rajpar, and Zakaria (2013) The divisions are based on data from 207 undergraduate subjects. High score indicates high self-monitoring and low score indicates low self-monitoring. It is a modified self-administered scale to the teenage mothers. This modification was done as a result of suggestions from supervisors and other experts in Research. The adaptation made to this scale was in terms of language to fit in Kenyan context. The scale tested ability of the teenage mothers to monitor how they express their nonverbal behaviour, aware of self-presentation in any social situation. Permission to use this questionnaire is generally given and researchers do not have to seek for permission to use it. The pilot test carried out helped to ascertain the reliability of the tool in this study. Through pilot testing, the scale reported a Cronbach's alpha coefficient of 0.834 , which indicated a very high reliability according to Creswell (2014).

\section{DATA ANALYSIS}

Analysis was performed using SPSS, version 21. Pearson correlation was used to show the relationship between quantitative variables. Descriptive statistics in forms of means, frequencies, standard deviations and percentages were used to analyze the quantitative data of the participants. Qualitative data were transcribed and analyzed according to the emerging themes.

\subsection{Results Of The Study}

TABLE 1

Demographic characteristics of the teenage mothers

\begin{tabular}{llcc}
\hline \multicolumn{1}{c}{ Categories } & & Frequency (f) & Percentage $(\%)$ \\
\hline Age of participants & $12-16$ years & 5 & 5.0 \\
& $17-20$ years & 27 & 27.0 \\
& 20 years \&above & 68 & 68.0 \\
Birth Order & First Child & 44 & 44.0 \\
& Middle Child & 37 & 37.0 \\
Educational Level & Last Child & 19 & 19.0 \\
& Primary & 22 & 22.0 \\
Whom they live with at Home & Secondary & 78 & 78.8 \\
& & 23 & 23.0
\end{tabular}




$\begin{array}{lcc}\text { Father and Siblings } & 2 & 2.0 \\ \text { Alone } & 32 & 32.0 \\ \text { Relatives } & 19 & 19.0 \\ \text { Husband } & 4 & 4.0\end{array}$

\section{Source: Computed by researcher.}

Table 1 revealed socio-demographic characteristics of the teenage mothers. The finding showed that majority of the teenage mothers who participated in the study were 20 years and above $(68 \%)$ while $27 \%$ aged between 17 and 20 years. The lowest participation was realized from those ranging between the ages of 12 and 16 years. This means the level of social skills competence and life experience acquired in relation to self-concept depend on the age of the individual. Those within 20 years and above were majority_that got pregnant at their late adolescence stage while in senior secondary school and engaged in new role of parenting activities and other responsibilities before coming to the rehabilitation center.

In terms of birth order, the findings revealed that most of the teenage mothers who participated in the study were first child (44\%), another 37\% were middle child and $19 \%$ were last child. From the findings, most of the participants were first child of their parents. This could explain the assumption that in most cases, first child experiences financial dependency from the family, struggling with huge responsibility thereby making them vulnerable to early pregnancy. One of the participants narrated her ordeal:

I am the breadwinner in my family because my mother is very sick and cannot take care of the family. The responsibility of the family rest on my shoulder. I regret involving myself in this kind of situation where I have to take care of my child and my family, which is very difficult for me at this young age. The father of the child is not giving me any support and I feel so frustrated and sad that I allowed myself to be deceived because of poverty. (P1, Individual Interview, November 17, 2020)

In terms of educational level, The findings 5 indicate that majority of the teenage mothers (78\%) got pregnant while in secondary school while $22 \%$ of the participants got pregnant while in primary school. From the findings, most of the participants got pregnant while in secondary school, an indicator of low level of social skills in decision making among the teenagers making them vulnerable to early pregnancy. This could be used to draw conclusion on the importance of social skills training in all levels of learning institution in raising the self-concept of teenage mothers. Consistent with Mohr, Carbajal, and Sharma (2019)vfindings that educational levels impact teenage pregnancy in low- and middle-income family. The empirical evidence confirms the study of Sang (2015) who argued that teenage mothers from low-income background and poor educational attainment are likely to experience challenges in their everyday interpersonal relationship making them develop poor selfconcept.

In terms of who they live with at home, the result showed that $32 \%$ of the participants live alone, $23 \%$ live with their parents and siblings, $20 \%$ live with their mother and siblings, $19 \%$ live with their relative, $4 \%$ live with their husband (father of the baby) while $2 \%$ live with their father and siblings. The findings showed that most of the teenage mothers live alone with their baby. This could be used as an evident in drawing the conclusion that some of the teenage mothers experienced rejections and lack of support from families, friends and relatives forcing them to live alone... One of the participants said: When I ask for food to feed my child, my mother will tell me to go and look for the father of the child and collect food for my child. You are now a mother so take the responsibility of taking care of your child. I sent you to school to go and learn and better your life, you prefer to be a mother, sort yourself out. I have to cope with the abuse I receive from my mother on daily basis. She would call me all sorts of bad names and try to make me feel bad. She kept telling me to take my baby to the father since I have decided to become a mother at my age. I had no option than move out and live alone with my baby. (P2, Individual Interview, November 17, 2020).

The qualitative findings agree with the findings of Jiménez-Peña et al. (2019)vthat, verbal abuse and lack of support affects self-concept of teenage mothers and may lead to repeated pregnancy. The findings again confirm the findings of Miriti and Mutua (2019) and Mangeli, Rayyani, Cheraghi, and Tirgari (2017) that teenage mothers experience social stigma, lack of emotional and psychological support, and stress around new life adjustments. Psychosocial support has a lot to do with increased self-concept of the teenage mothers as the process of transition to new roles of motherhood require love and acceptance.

TABLE 2

Demographic Differences in Social Skills

\begin{tabular}{|c|c|c|c|c|}
\hline & & $\begin{array}{l}\text { Relationship } \\
\text { Management }\end{array}$ & Assertiveness & Self-Monitoring \\
\hline \multirow{3}{*}{ Age } & $12-16$ & 3.60 & 2.32 & 3.60 \\
\hline & $17-20$ & 3.48 & 2.68 & 3.23 \\
\hline & 20-above & 2.40 & 2.97 & 2.69 \\
\hline \multirow[t]{3}{*}{ Birth Order } & First Child & 3.40 & 2.90 & 2.90 \\
\hline & Middle Child & 3.47 & 2.82 & 2.75 \\
\hline & Last Child & 3.44 & 2.83 & 3.11 \\
\hline \multirow[t]{2}{*}{ Educational Level } & Primary & 3.38 & 2.85 & 3.00 \\
\hline & Secondary & 3.45 & 2.85 & 2.86 \\
\hline \multicolumn{5}{|c|}{ Whom they live with } \\
\hline & $\begin{array}{l}\text { Father, Mother \& } \\
\text { Siblings }\end{array}$ & 3.44 & 2.99 & 2.77 \\
\hline & Mother \& Siblings & 3.46 & 2.92 & 2.93 \\
\hline
\end{tabular}

Please cite this article as: Okore, C., Asatsa, S., \& Ntarangwe, M. (2021). Effect of Social Skills Training on Self Concept of Teenage Mothers, A case study of Training College in Kenya. Journal of Social Sciences and Economic Review, 3(2), 1-09. doi.org/10.36923/ijsser.v3i2.102 


$\begin{array}{llll}\text { Father \& Siblings } & 3.10 & 2.90 & 3.25 \\ \text { Alone } & 3.26 & 2.80 & 2.78 \\ \text { Relatives } & 3.71 & 2.70 & 3.10 \\ \text { Husband } & 3.45 & 2.95 & 2.93\end{array}$

\section{Source: Computed by researcher}

Table 2 compared the demographic differences in Social Skills. The findings showed that the mean score of social skills was highest at the lower age in response to relationship management $12-16$ (mean $=3.60$ ), followed by 17- 20 (mean $=3.48)$. Surprisingly, assertiveness was the lowest at the lower ages $12-16($ mean $=2.32)$ and the highest at ages 20 and above (Mean $=3.48)$. In response to self-monitoring, it was highest again at the lower ages $12-16$ (mean =3.60), followed by 17- 20 $($ mean $=3.23)$. The findings showed that assertiveness increases as individual transits from early adolescence to late adolescence as seen from the sample in the present study. Interestingly, relationship management is highest at the emerging of adolescence; and it reduces at late adolescence from the sample of the present study. Again, a similar pattern occurs in self-monitoring where it is highest at the emerging of adolescence; and it reduces at late adolescence from the sample of the present study. The findings showed that social skill has influence on age of the participants.

In terms of birth order, the findings showed that relationship management was the highest prevalence across the three different birth order with first child (mean $=3.40)$, middle child (mean $=3.47)$ and last child $($ mean $=3.44)$. In response to self-monitoring, last child scored the highest (mean $=3.11$ ). Interestingly, the findings showed that first child is high in assertiveness and last child high in self-monitoring (mean $=2.90$ ). This may be due to the assumption that first child has the knowledge of her thought, feelings, and capabilities to regulate themselves as they are seen as role model to the younger siblings. Again, this means last children are more aware of their behaviour in social situation that than the first and middle child. The findings showed that relationship management is highest across the three-birth order. The findings also revealed that social skill has influence on birth order of the participants

In terms of educational level, it revealed that those that got pregnant while in primary school reported highest mean score across all the three social skills constructs. The component with highest score was relationship management with a mean score of 3.38 for primary level and 3.45 for secondary level. The means differences were also found in the self-monitoring of the teenage mothers at the primary level that scored high $($ mean $=3.00)$, followed by secondary level $($ mean $=2.86$ ).

For the sample for this current study, it showed that those who got pregnant while in primary and secondary school have had better relationship management. The findings equally showed that those who got pregnant while in primary school got better self-monitoring behaviour competence than those in secondary school level got. When comparing the mean scores, teenage mothers who got pregnant while in primary school (3.00) are found to be better than secondary (2.86) in their level of social skills.

In terms of whom they live with, the finding showed high consistency in mean score across whom they live with in relation to relationship management with father, mother and siblings (mean $=3.44)$, mother and siblings $($ mean $=3.46)$, father and siblings (mean $=3.10)$, alone (mean $=3.26$ ), relatives (mean $=3.71)$ and husband (mean $=3.45)$. Again, the result showed higher mean score in relation to assertiveness with those who live with who they live with their mother and siblings (mean = 3.92). Also, in relation to self-monitoring across whom they live with showed highest mean score with their father and siblings $($ mean $=3.25$ ) followed by Relatives (mean $=3.10$ ). The findings showed that their level of assertiveness is influence by whom they live with depending with the kind of psychosocial support and assistance they receive. This could be due their parent's attitude and level of acceptance and understand of their situation. The empirical findings concur with Kumar et al. (2018) that emphasis on the psychosocial support for teenage that influence their social skills enabling them adjust to their new role of young motherhood.

Table 3

Demographic Differences in Self- Concept

\begin{tabular}{|c|c|c|c|c|}
\hline & & Self-Awareness & Self -Efficacy & Self-Esteem \\
\hline \multirow[t]{3}{*}{ Age } & $12-16$ & 2.88 & 2.96 & 3.14 \\
\hline & $17-20$ & 2.65 & 3.01 & 2.82 \\
\hline & 20-above & 2.66 & 3.40 & 2.56 \\
\hline \multirow[t]{3}{*}{ Birth Order } & First Child & 2.69 & 3.31 & 2.64 \\
\hline & Middle Child & 2.77 & 3.23 & 2.82 \\
\hline & Last Child & 2.42 & 3.25 & 2.54 \\
\hline \multirow[t]{2}{*}{ Educational Level } & Primary & 2.65 & 3.37 & 2.73 \\
\hline & Secondary & 2.67 & 3.24 & 2.64 \\
\hline \multicolumn{5}{|c|}{ Whom they Live with } \\
\hline & $\begin{array}{l}\text { Father, Mother \& } \\
\text { Siblings }\end{array}$ & 2.85 & 3.50 & 2.49 \\
\hline & Mother \& Siblings & 2.72 & 3.08 & 2.84 \\
\hline & Father \& Siblings & 2.85 & 3.00 & 3.10 \\
\hline & Alone & 2.48 & 3.35 & 2.41 \\
\hline & Relatives & 2.72 & 3.13 & 2.80 \\
\hline & Husband & 2.50 & 3.10 & 2.25 \\
\hline
\end{tabular}


Source: Computed by the researcher.

Table 3 compared the demographic differences in self-concept of the teenage mothers. The findings showed that mean scores of self-efficacy was high among teenage mothers between the ages 20 years and above and self-esteem high between ages 12- 16 years respectively. Consequently, the mean score of self-efficacy is higher across the different birth order, educational level and the person they live with at home.

\subsection{Correlation between Self Concept and Assertiveness}

The study sought to examine the relationship between the self-concept of teenage mothers and the level of assertiveness. The results of the analysis done were displayed in table 4 .

Table 4

Correlation between Self Concept and Assertiveness

\begin{tabular}{lcc}
\hline Self - Concept & & Assertiveness \\
\hline Self- Awareness & $\mathrm{R}$ & .151 \\
& $\mathrm{Sig}$. & .136 \\
Self- Efficacy & $\mathrm{R}$ & .061 \\
& $\mathrm{Sig}$. & .546 \\
Self Esteem & $\mathrm{R}$ & .029 \\
& $\mathrm{Sig}$ & .775 \\
& $\mathrm{~N}$ & 100 \\
\hline
\end{tabular}

Table 4 revealed the Level of assertiveness on self-concept of teenage mothers in Kibera, Nairobi.

The result in table 4 portrayed a very weak positive relationship between assertiveness skills and self-awareness of teenage mothers $(\mathrm{p}<0.05, \mathrm{r}=.151)$. This means, as assertive behaviour increases, teenage mother's self-awareness equally increases. This implies, learning assertive techniques are considered as tools for coping skills with a variety of life stressors. Increasing assertive behavior becomes an expression of person's feelings. Consistent with Ghodrati, Tavakoli, Heydari, and Akbarzadeh (2016) study that assertiveness is a core human behaviour, is key to interpersonal relationships, and needs to be promoted among adolescents. Qualitative findings indicated that some of the teenage mother have improved their self-awareness through psychosocial training offered at the rehabilitation center. This was evident from one of the participants who said:

I am a final year student in catering department. I go my baby when I was in form four, which led to my poor performance in KCSE. All my dreams of going to the university and aspirations were shattered and I still regret what happened to me. My parents were mad at me at first because I brought shame to them. When I came to this center, I was not able to speak out or express myself without getting angry or pointing accusing finger on others. The center invites some people to come here once in a week to talk to us about entrepreneurship as well as give us psychosocial support. I am beginning to express myself without much fear gradually since I came to this center. I have grown compared to when I first came here. (P 6, Individual Interview, November 17, 2020)

The study found no correlation between assertiveness and self-efficacy among teenage mothers $(p<0.05, r=.061)$. This means, assertive behaviour among teenage mothers has no impact on their self-efficacy. Again, the study found no correlation between assertiveness and self-esteem among teenage mothers $(\mathrm{p}<0.05, \mathrm{r}=.029)$. This shows that as parents show less involvement and lack of support on their teenage mothers, the teenage mother's self-esteem decreases. The results from the current study contradict the findings done by Rutter et al. (2017)that reported assertive training to have the capacity to motivate, enhance students' self-efficacy among secondary school students. In line with the report, qualitative findings indicated that teenage mother's parents' attitude towards them contributed highly to their level of low self-esteem. One of the participants narrated:

I am a first-year student in hair dressing department. I got my baby when I was in form 2 and since then I have been living in regrets. My parents rejected me and sent me away to go and look for the father of my baby. The worst of it is that the boy that got me pregnant rejected my baby and I and is nowhere to be found. I cry and get hurt each time I remember the situation I got myself into. I live alone with my child and taking care of this baby has been a hell especially now the baby is sick. This rehabilitation center is the motivation, has helped me get through my day, my schoolwork and with my baby. (P7, Individual Interview, November 18, 2020)

\subsection{Correlation between Self Concept and Self-Monitoring}

The study sought to examine the relationship between the self-concept of teenage mothers and self-monitoring competence. The findings were presented in table 14 .

Table 5

Correlation between Self Concept and Self-Monitoring

\begin{tabular}{llll}
\hline \multicolumn{1}{r}{ Self - Concept } & & \multicolumn{1}{c}{ Self - Monitoring } \\
\hline Self- Awareness & $\mathrm{R}$ & .036 & \\
\multirow{2}{*}{ Self- Efficacy } & Sig. & .724 & \\
& $\mathrm{R}$ & $-.323^{* *}$ & \\
Self Esteem & Sig. & .001 & \\
& $\mathrm{R}$ & $.211^{*}$ &
\end{tabular}




Sig. $\quad .035$

$\mathrm{N}$

100

Source: Computed by the researcher.

From table 5, the current study found no correlation between self-monitoring and self-awareness among teenage mothers $(\mathrm{p}<0.05, \mathrm{r}=.036)$. This means self-monitoring behaviour among teenage mothers has no impact on their self-awareness. The study found weak negative correlation between self-monitoring and self-efficacy among teenage mothers $(p<0.01, r=-.323)$. This means increase in self-monitoring behaviour among teenage mother's decreases with self-efficacy. Again, the study found weak positive correlation between self-monitoring and self-esteem among teenage mothers $(\mathrm{p}<0.05, \mathrm{r}=.211)$. This means increase in self-monitoring behaviour can increase teenage mother's self-esteem. The results from the current study also showed consistency with earlier studies done by Lawrence and Saileela (2019) that reported a correlation analysis and found that there is a low positive relationship between self-concept and self-monitoring of higher secondary students.

\section{DISCUSSION}

The present study was aimed to assess the effect of social skills training in enhancing self-concept of teenage mother. The findings showed that assertiveness increases as individual transits from early adolescence to late adolescence as seen from the sample in the present study. Interestingly, relationship management is highest at the emerging of adolescence; and it reduces at late adolescence from the sample of the present study. Again, a similar pattern occurs in self-monitoring where it is highest at the emerging of adolescence; and it reduces at late adolescence from the sample of the present study. The findings showed that social skill has influence on age of the participants.

The findings showed that relationship management was the highest prevalence across the three different birth order. In response to self-monitoring, last child scored the highest. Interestingly, the findings showed that first child is high in assertiveness and last child high in self-monitoring. This may be due to several mentorship programs offered at the rehabilitation center assumption that first child has the knowledge of her thought and are seen as role model to the younger siblings. According the study finding, last child is more aware of their behaviour in social situation than the first and middle child is.

The findings showed that relationship management is highest across the three-birth order. The findings also revealed that social skill has influence on birth order of the participants. The findings revealed that those that got pregnant while in primary school reported highest mean score across all the three social skills constructs. For the sample for this current study, it argued that those who got pregnant while in primary and secondary school have had better relationship management. The findings equally showed that those who got pregnant while in primary school got better self-monitoring behaviour competence than those in secondary school level got. The findings showed that their level of assertiveness is influence by whom they live with depending with the kind of psychosocial support and assistance they receive. This could be due their parent's attitude and level of acceptance and understand of their situation.

The findings showed that age of the participants has influence on their self-concept as they undergo life process into motherhood. The finding concluded that they grow in self-concept as they transit from early adolescence to late adolescence. This finding supported the finding of Lawrence and Saileela (2019) that self-esteem decreases with age. Adolescent's selfesteem is higher between 12 and 14 years and from ages 23 above years have the lowest self-esteem. In terms of birth order, the findings showed that self-concept is not consistent with birth order. The findings showed that self-concept has no significant influence on birth order of the participants. However, qualitative findings indicated that some teenage mothers who are first child got pregnant following their mother's footstep hence, influencing their self-concept. One of the participants asserted: My mom is 32 years old and a single mom, well I follow her footsteps she got pregnant at the age of 17." "My mother did not get rid of me so I did not want to get read of mine. My child has brought me good luck, the reason why I am in this rehabilitation center and I have benefitted a lot from the center. The center teaches us positive parenting and the need to bond with our child and being a responsible parent. It teaches us not to relent in life struggles no matter the life challenges in order to avoid repeat pregnancy. (P3, Individual Interview, November 17, 2020).

The findings showed that those that got pregnant while in primary and secondary school reported highest mean score in self-efficacy. For the sample for this current study, it showed that those who got pregnant while in primary and secondary school have high self-efficacy while their self-esteem decreases while in secondary. Teenage mothers who got pregnant while in primary school are found to be better than secondary in their self-concept.

The findings also showed that self-esteem and self-awareness are influence by the amount of love, acceptance and support shown to teenage mothers. It is clear that those who live with the father of their baby has issues with self-esteem and self-awareness. Some of them could be going through abusive relationship if the relationship was imposed on one party. This was evident through the experience of a participant who said:

My parents are very aggressive towards me, raining insult on me all the. The song I hear is to go and look for the father of my child. I take in all the abuses because I have nowhere to go with my baby. I only agree to stay there with my parents under the same roof to enable me go out to look for causal work to take of my baby and myself. After much pressure, I moved in with the father of my baby. I had a dream of going to the university but now all my dreams are shattered. My man beats all the time when there is no food in the house. I am struggling to feed my new family since my parents has rejected my baby and I. (P4, Individual Interview, November 17, 2020)

Sending teenage mother to live with the father of the baby portrays a society where the parents and family members indirectly encourage teenage pregnancy. This relationship can allow the teenagers to continue with sexual relation and susceptible to abusive relationship. This has negative influence on their self-concept and sends a confusing message to their younger generation about sex and motherhood.

\section{CONCLUSION}

Please cite this article as: Okore, C., Asatsa, S., \& Ntarangwe, M. (2021). Effect of Social Skills Training on Self Concept of Teenage Mothers, A case study of Training College in Kenya. Journal of Social Sciences and Economic Review, 3(2), 1-09. doi.org/10.36923/ijsser.v3i2.102 
The study concluded that significant number of teenage mothers have a problem with relationship management and assertiveness. There is a weak positive correlation between assertiveness, self-awareness, self-efficacy and self-esteem. Therefore, it is important to promote the level of assertiveness amongst teenage mothers to help them gain self-confident and self-expression without aggression. Evidence abounds in this study that social skills training has proven to be effective in enhancing the self-concept of teenage mothers and holistic formation through mentorship program. Generally, the qualitative findings of the present study indicated that there is need to improve the self-concept of teenage mothers through family psychological support. The study generally concludes that self-concept of teenage mothers is being affected by lack of psychological support, forgiveness and acceptance from the family. Intervention suggested included being emotionally present, psychological support, and love by parents to teenage mothers.

\section{DECLARATION OF INTEREST}

The authors report no conflicts of interest. The authors alone are responsible for the content and writing of this paper. All authors made a substantial contribution to conception and design of the study and were involved in drafting and reviewing the manuscript. All authors have read and approved the final manuscript.

\section{ACKNOWLEDGMENT}

The researchers would like to thank the participants and the administration of the Vocational College for their valuable contributions.

\section{REFERENCES}

Alessandri, G., Vecchione, M., Eisenberg, N., \& Laguna, M. (2015). On the factor structure of the Rosenberg (1965) General Self-Esteem Scale. Psychological assessment, 27(2), 621-632.

Anyamene, A., \& Obumneke, N. G. (2021). Effect of Modelling Technique on Low Self-Concept Among Secondary School Students in Imo State. Journal of Guidance, 5(1), 118-126.

Bing, D., Rajpar, M. N., \& Zakaria, M. (2013). Avian richness and habitat characteristics in primary and logged hill dipterocarp tropical rainforest of peninsular Malaysia. Malayan Nature Journal, 65(4), 300-316.

Boobpamala, S., Kongvattananon, P., \& Somprasert, C. (2019). Early Management of Depression in Adolescent Pregnancy: An Integrative Review. The Journal of Behavioral Science, 14(1), 97-113.

Creswell, J. W. (2014). A concise introduction to mixed methods research: SAGE publications.

Creswell, J. W., Plano Clark, V., Gutmann, M. L., \& Hanson, W. E. (2003). An expanded typology for classifying mixed methods research into designs. A. Tashakkori y C. Teddlie, Handbook of mixed methods in social and behavioral research, 209-240.

Ellis-Sloan, K., \& Tamplin, A. (2019). Teenage mothers and social isolation: The role of friendship as protection against relational exclusion. Social Policy and Society, 18(2), 203-218.

Fearnley, B. (2018). Contemporary young motherhood: Experiences of hostility. Journal of Children's Services, 13(2), 64-78.

Gaspar, T., Cerqueira, A., Branquinho, C. S. d. S., \& Matos, M. G. (2018). The effect of a social-emotional school-based intervention upon social and personal skills in children and adolescents. Journal of Education and Learning, 7(6), 110.

Ghodrati, F., Tavakoli, P., Heydari, N., \& Akbarzadeh, M. (2016). Investigating the relationship between self-esteem, assertiveness and academic achievement in female high school students. Health Science Journal, 10(4), 1-5.

Jiménez-Peña, A., Pantaleón-García, J., Hernández-Escobar, C. E., Cisneros-Rivera, F., Ramos-Reyes, A., De Alba-Marquez, I., \& Ruiz-Carranza, C. A. (2019). 1. Abusive Behavior Silently Increases Low Self-esteem and Depression in Teenage Pregnancy Patients: A Mexican Cohort. Journal of Pediatric and Adolescent Gynecology, 32(2), 193. doi:DOI:https://doi.org/10.1016/j.jpag.2019.02.002

Kuasit, U., Chunuan, S., Hatthakit, U., \& Bullock, L. F. (2018). The Effects of the resilience-enhancing nursing program on life goals among pregnant teenagers: A Randomized controlled trial. Songklanagarind Journal of Nursing, 38(1), 35-45.

Kumar, S., Stecher, G., Li, M., Knyaz, C., \& Tamura, K. (2018). MEGA X: molecular evolutionary genetics analysis across computing platforms. Molecular biology and evolution, 35(6), 1547-1549.

Lawrence, A. A., \& Saileela, K. (2019). Self-concept and self-regulation of higher secondary students. i-Manager's Journal on Educational Psychology, 13(1), 45-53.

Mangeli, M., Rayyani, M., Cheraghi, M. A., \& Tirgari, B. (2017). Exploring the challenges of adolescent mothers from their life experiences in the transition to motherhood: a qualitative study. Journal of family \& reproductive health, 11(3), $165-173$.

Miriti, J. M., \& Mutua, M. N. (2019). Teenage Pregnancies And Girls Education Capabilities In Nzambani Ward Kitui County In Kenya: School And Community Perspective. International Journal of Gender Studies, 4(1), 59-84.

Mohamed, N. A. E.-M., \& Mahmoud, G. A. E.-R. (2018). Self-concept and self-esteem among adolescent pregnant women at General Assiut Hospital, Assiut City. Egyptian Nursing Journal, 15(2), 93-101.

Mohr, R., Carbajal, J., \& Sharma, B. B. (2019). The influence of educational attainment on teenage pregnancy in low-income countries: A systematic literature review. Journal of Social Work in the Global Community, 4(1), 19-31.

Morowatisharifabad, M. A., Baghernezhad Hesary, F., Sharifzadeh, G. R., Miri, M., \& Dastjerdi, R. (2019). Investigating the life skills and self-esteem in teenage girls in Birjand, Iran. International Journal of Pediatrics, 7(6), 9623-9630.

Nihayati, H. E., Tristiana, R. D., Junata, A. S. P., \& Yusuf, A. (2017). Effect of Social Skills Training: Social Interaction Capabilities towards Social Isolation Clients. Advances in Health Sciences Research, 3, 121-125. 
Okore, C., Asatsa, S., \& Ntarangwe, M. (2021). The Effect of Social Skills Training on Self Concept of Teenage Mothers at St. Charles Lwanga Vocational Training College in Kibera Nairobi-County, Kenya. Journal of Sociology, Psychology \& Religious Studies, 3(1), 1-17.

Organization, W. H. (2018). Preventing early pregnancy and poor reproductive outcomes among adolescents in developing countries [en línea]. Geneve, Switzerland. . In.

Paik, S. J. (1992). Self concept of pregnant teenagers. Journal of health \& social policy, 3(3), 93-111.

Parray, W. M., \& Kumar, S. (2017). Impact of assertiveness training on the level of assertiveness, self-esteem, stress, psychological well-being and academic achievement of adolescents. Indian Journal of Health and Wellbeing, 8(12), 1476-1480.

Rutter, H., Savona, N., Glonti, K., Bibby, J., Cummins, S., Finegood, D. T., . . Moore, L. (2017). The need for a complex systems model of evidence for public health. The lancet, 390(10112), 2602-2604.

Sámano, R., Martínez-Rojano, H., Robichaux, D., Rodríguez-Ventura, A. L., Sánchez-Jiménez, B., de la Luz Hoyuela, M., . . Segovia, S. (2017). Family context and individual situation of teens before, during and after pregnancy in Mexico City. BMC pregnancy and childbirth, 17(1), 1-16.

Sang, C. C. (2015). Relationship between students' family Socio-economic Status, Self esteem. International Journal of Education and Research, 3(2), 647-656.

Shanmugam, V., \& Kathyayini, B. (2017). Assertiveness and self-esteem in Indian adolescents. Galore Int. J. Health Sci. Res, 2(4), 8-13. 